\title{
Homossexualidade e o direito à saúde: um desafio para as políticas públicas de saúde no Brasil
}

Homosexuality and the right to health: a challenge for health policies in Brazil

Grayce Alencar Albuquerque ${ }^{1}$, Cíntia de Lima Garcia ${ }^{2}$, Maria Juscinaide Henrique Alves ${ }^{3}$, Cicera Monalisa Holanda Teles de Queiroz ${ }^{4}$, Fernando Adami ${ }^{5}$

1 Doutoranda em Ciências da Saúde pela Faculdade de Medicina do ABC (FMABC) - Santo André (SP), Brasil. Coordenadora e professora do curso de Enfermagem da Faculdade de Juazeiro do Norte (FJN) Juazeiro do Norte (CE), Brasil.

geycy@oi.com.br

${ }^{2}$ Mestranda em Ciências da Saúde pela Faculdade de Medicina do ABC (FMABC) - Santo André (SP), Brasil. Professora da Faculdade de Juazeiro do Norte (FJN) Juazeiro do Norte (CE), Brasil. cintiadelimagarcia@hotmail.com

${ }^{3}$ Graduada em Enfermagem pela Faculdade de Juazeiro do Norte (FJN) Juazeiro do Norte (CE), Brasil.. juscinaidehenrique@hotmail.com

${ }^{4}$ Graduada em Enfermagem pela Faculdade de Juazeiro do Norte (FJN) Juazeiro do Norte (CE), Brasil.

monalizaholandaa@hotmail.com

${ }^{5}$ Doutor em Saúde Pública pela Faculdade de Medicina do ABC (FMABC) - Santo André (SP), Brasil.

adamifernando@uol.com.br
RESUMO: Objetivou-se evidenciar a atuação das políticas públicas direcionadas à saúde da população homossexual brasileira. Trata-se de uma revisão integrativa da literatura, realizada na Scientific Eletronic Library Online (SciELO) e na Literatura Latino-Americana e do Caribe em Ciências da Saúde (Lilacs), utilizando os Decs: políticas públicas, assistência integral à saúde e homossexualidade. A saúde LGBT é apontada como vulnerável mesmo após a publicação de importantes documentos que garantem o acesso e a inclusão do grupo na saúde. A fragilidade na efetivação das propostas preconizadas vão ao encontro ao atendimento discriminatório e heteronormativo prestado pelos profissionais de saúde.

PALAVRAS-CHAVE: Políticas Públicas; Assistência integral à saúde; Homossexualidade

ABSTRACT: We aimed to highlight the role of public health policies for the homosexual population in Brazil. We performed an integrative literature review using the Scientific Electronic Library Online (SCiELO) and Latin American and Caribbean Health Sciences (LILACS), using the Decs: public policies, comprehensive care health and homosexuality. The LGBT Health is seen as vulnerable even after the publication of important documents that ensure access and inclusion in the group health. The weakness in the effectiveness of the recommended proposals go against discriminatory and heteronormative care provided by health professionals.

KEYWORDS: Public Policies; Comprehensive health care; Homosexuality. 


\section{Introdução}

Ao serem abordadas questóes inerentes à sexualidade, assinala-se que a mesma é uma constituinte fundamental e imprescindível para a existência de um ser, estando presente em toda a extensão de sua vida e dos contatos pessoais que nela são desenvolvidos, tanto nas relações interpessoais - aquelas mantidas entre pessoas inseridas em um meio social - como nas relaçóes intrapessoais que envolvem a subjetividade de cada indivíduo e, mais detidamente, sua relação com ele mesmo -, que acabam por determinar os modos de ser, de se ver, de pensar e de se revelar para a sociedade, pois a sexualidade é o principal elemento estruturante da identidade e da personalidade, já que unifica seus níveis biológico, psicológico e social (ABDO; GUARIGLIA-FILHO, 2004).

Nesse contexto, as formas de expressar a sexualidade são determinadas por uma complexa interação de fatores. Podem ser afetadas pelo(s) relacionamento(s) do indivíduo com outro(s), por circunstâncias de sua vida ou pela cultura em que vive (ABDO; GUARIGLIAFILHO, 2004), o que denota, portanto, ser o modo de expressão da sexualidade algo construído gradualmente durante o crescimento e o desenvolvimento psicossocial do indivíduo, diante de suas relaçóes com outras pessoas, refletindo experiências evolutivas do ser humano durante o seu ciclo vital, delimitadas pelo que, comumente, optou-se por caracterizar como performance e identidade de gênero.

O gênero como elemento constitutivo das relaçôes sociais entre homens e mulheres é uma construção social, histórica, política e econômica. É construído e alimentado com base em símbolos, normas e instituiçôes que definem modelos de masculinidade e feminilidade. Desse modo, o sistema sexo/gênero operacionaliza relaçóes de poder (PISCITELLI, 2001), inicialmente, delimitando e reforçando padróes de comportamento, aceitáveis ou não para homens e mulheres, e, mais recentemente, permitindo generalizaçôes para a interpretaçáo de novas formas de expressão da sexualidade dos indivíduos, como a diversidade sexual.

Falar da diversidade sexual é resgatar elementos para compreender significados e dar sentido a essa construção social, que se revela a partir de uma identidade sexual (TONIETTE, 2006). Pereira e Leal (2005), por exemplo, definem a identidade sexual a partir de quatro critérios: o sexo biológico (caracterizado pela definição genética); a identidade do gênero (a percepção de cada indivíduo como sendo homem ou mulher); os papéis sexuais sociais (definidos pelas características socialmente estabelecidas ao feminino e ao masculino, numa perspectiva de gênero); e a orientação sexual (caracterizada pelo desejo afetivo-sexual de um sujeito em face de outro, seja este do sexo oposto ou do mesmo sexo).

Portanto, a discussão de conceitos, como identidade de gênero e identidade sexual, denota a abordagem de constructos mutáveis e dinâmicos. Nesse sentido, conceber a identidade heterossexual como a normal e natural é negar que toda e qualquer identidade (sexual, étnica, de classe ou de gênero) seja uma construção social, que toda identidade culmine em um processo dinâmico, portanto, nunca acabado, pronto ou fixo, mas sempre remodelado (LOURO, 1997).

Assim, quando se fala em homossexualidade, aqui definida como a orientação sexual que envolve a atração afetivo-sexual entre pessoas do mesmo sexo, revela-se que ela sempre existiu ao longo da história, nas mais diferentes sociedades e culturas, tendo permitido posicionamentos sociais, ora de aceitação ora de repulsa (TONIETTE, 2006), sendo, atualmente, muito criticada por ir contra a naturalização dos papéis sociais de homens e mulheres.

No entanto, falar da homossexualidade é falar da sexualidade humana, da diversidade sexual, resgatando elementos para compreender significados e sentidos dessa construção social (TONIETTE, 2006), ainda repudiada e discriminada pela sociedade. De fato, apesar da antiga construção e da popularização da homossexualidade, uma pesquisa realizada em 102 municípios brasileiros, com uma amostragem de 2363 entrevistados, constatou que $89 \%$ dos participantes foram contra a homossexualidade masculina e $88 \%$ contra a lesbiandade e a bissexualidade de mulheres (VALADÁO; GOMES, 2011). Ainda, os autores complementam afirmando que o resultado pode ilustrar a ideia hegemônica presente no imaginário social de que a sexualidade deve ser heterossexual, e que aceitar o contrário pode significar ir de encontro a algo considerado natural. 
Assim, em um contexto de enfrentamento do preconceito e da discriminação, surgem os movimentos sociais organizados por essa parcela populacional e pelos grupos interligados, hoje reconhecidos como Movimento LGBT (lésbicas, gays, bissexuais e transgêneros) Brasileiro. Na realização desse movimento tramita um conjunto de reivindicaçóes, entre as quais: a livre expressão de sua orientação sexual, a mudança do nome em documentos de identidade, o acesso a políticas de saúde e a proteção do Estado frente à violência motivada pelo preconceito (CARRARA, 2010).

Quando se correlacionam homossexualidade e saúde, as práticas de reivindicaçóes dessas vertentes surgem, no Brasil, na virada do século XX para o século XXI, em consonância com a noção dos direitos sexuais. A partir de então, passa-se a considerar as necessidades desse grupo populacional e a pensar em políticas de saúde voltadas aos mesmos (BARBOSA; FACCHINI, 2009).

Desde então, percebem-se avanços importantes no contexto brasileiro, como o Programa Brasil Sem Homofobia e a Política de Assistência Integral à saúde da população LGBT. No entanto, ainda observa-se, no Brasil e no mundo, a dificuldade enfrentada pela população LGBT diante das diversas formas de violência e das discriminaçóes vivenciadas em decorrência da livre orientaçáo sexual. Além disso, o acesso do grupo LGBT à saúde é marcado por obstáculos, como atendimento discriminatório por parte dos profissionais nas unidades, condutas inadequadas, constrangimentos, conotaçóes preconceituosas ou mesmo ofensas verbais proferidas pelos profissionais (GUTIERREZ, 2007; HECK et al., 2006).

Portanto, constitui-se como objetivo deste estudo evidenciar, através das produções científicas presentes no Brasil, a existência e a atuação das políticas públicas especificamente direcionadas às necessidades de saúde da população homossexual brasileira.

Logo, a presente revisão busca reunir os principais pontos desse contexto, possibilitando à população em geral e, principalmente, aos profissionais de saúde a visão e a reflexão acerca da atual conjuntura da saúde LGBT, sinalizando aspectos desafiadores da formulação e da implantação de políticas que, efetivamente, atendam às demandas desse público.

\section{Método}

Trata-se de uma revisão integrativa da literatura, definida como aquela em que resultados de pesquisas sobre determinado assunto ou questionamento são analisados e sintetizados, com o objetivo de aprofundar o conhecimento sobre uma área em particular (MENDES, 2008).

Figura 1. Fluxograma mostrando a seleção do estudo para a revisão: estratégia de pesquisa, número de registros identificados, incluídos e excluídos

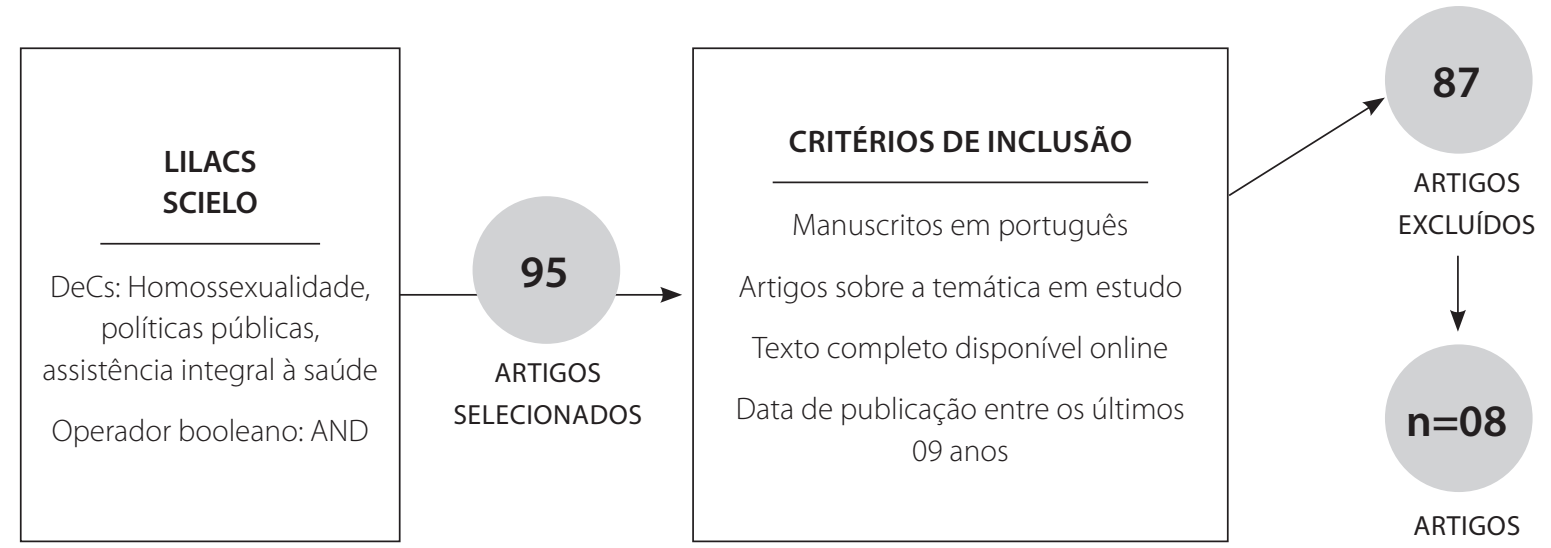


Para tanto, o levantamento bibliográfico foi realizado na Scientific Eletronic Library Online (SciELO) e na Literatura Latino-Americana e do Caribe em Ciências da Saúde (Lilacs), utilizando os descritores: políticas públicas, assistência integral à saúde e homossexualidade, pesquisados na página eletrônica dos Descritores em Ciências da Saúde (DeCs). Para aumentar o escopo da revisão, foi utilizado o operador booleano and, como segue: DeCs 1 and DeCs 2 and DeCs 3 .

Foram considerados apenas os artigos identificados como sendo do ano de 2004 até maio de 2013, tomando-se como marco o ano do lançamento do programa Brasil sem Homofobia: 2004.

A análise seguiu critérios de elegibilidade previamente determinados. Os critérios de inclusão foram; a) manuscritos escritos em português; b) artigos sobre a temática em questão; c) pesquisas originais e revisóes narrativas e integrativas; d) artigos com texto completo, disponíveis online; e e) data de publicação entre os últimos nove anos.

Foram excluídas da amostra pesquisas ainda não publicadas, monografias, dissertaçóes e teses.

Após a leitura criteriosa da amostra selecionada, os dados foram analisados e apresentados descritivamente.

\section{Resultados}

As buscas realizadas resultaram em um total de 95 artigos. Com o emprego dos critérios de inclusão, foram selecionados oito artigos (Figura 01).

A Tabela 01 mostra uma visão geral de todos os artigos incluídos na amostra final, além dos autores, ano de publicação, objetivos e principais resultados.

Para a apresentação dos resultados, os artigos foram avaliados levando-se em consideração a fonte primária do estudo, a quantidade de autores, a categoria profissional e a titulação máxima dos pesquisadores, o ano de publicação, a região da publicação e os resultados encontrados.

De acordo com a classificação das pesquisas, a maioria enquadra-se em revisões narrativas e integrativas ( $\mathrm{n}=$ quatro), seguidas de três artigos originais, com abordagem qualitativa, e um relato de caso.
Quanto à região originária da publicação, foi possível identificar o Sudeste e o Centro-Oeste como as regióes com maior número de artigos selecionados pela presente revisão, ambas com três produçóes. Em seguida, destacam-se o Ceará e o Sul, com um artigo selecionado de cada Regiáo.

Investigou-se, ainda, a quantidade de autores envolvidos nas publicaçóes, os quais totalizaram 19, uma média de, aproximadamente, dois autores por artigo. A maioria das amostras possuía dois autores por artigo ( $\mathrm{n}=$ quatro), seguidas das com quatro autores/artigo ( $\mathrm{n}=$ dois), de um artigo com três pesquisadores e um com apenas um autor.

Ao analisar a categoria profissional dos pesquisadores, observou-se que quatro são sociólogos, quatro enfermeiros, três psicólogos e dois terapeutas ocupacionais, havendo, ainda, um representante para cada uma das áreas a seguir: medicina, jornalismo, assistência social, direito e filosofia.

Com relação à titulação máxima dos autores, observou-se que a maioria é composta por doutores $(\mathrm{n}=11)$, além de constarem quatro mestres, dois especialistas e dois graduados. Considera-se o potencial envolvimento dos doutores e mestres com as publicaçóes, revelando o estímulo voltado para que os mesmos contribuam para o aumento do conhecimento cientifico.

Os anos em que houve maior número de publicaçôes foram 2012, 2011 e 2006 - com seis publicaçôes, duas em cada ano -, seguidos pelos anos de 2008 e 2009, com apenas uma publicação cada.

\section{Discussão}

Ao passo que surgem as buscas pelos direitos de cidadania, fica evidente que, no Brasil, ainda é escasso o conhecimento das necessidades em saúde da população homossexual, conhecimento esse que se evidencia como primordial para fomentar o desenvolvimento das políticas de saúde direcionadas à categoria.

Estudos indicam que a população em questão apresenta demasiada resistência à procura dos serviços de saúde, o que, em suma, evidencia o contexto discriminatório existente, organizado em função de uma 
Tabela 1. Síntese dos artigos selecionados para a revisão

\begin{tabular}{|c|c|c|}
\hline $\begin{array}{l}\text { CARDOSO E } \\
\text { FERRO }\end{array}$ & $\begin{array}{l}\text { Contribuir para a reflexão sobre } \\
\text { alguns dos fatores que podem in- } \\
\text { terferir, de maneira substancial, no } \\
\text { processo de saúde da população } \\
\text { LGBT. }\end{array}$ & $\begin{array}{l}\text { Sublinha a importância da atenção dos profissionais da saúde frente às } \\
\text { reações em cadeia que implicam o processo de vulnerabilidade e que } \\
\text { conduzem ao adoecimento dessa população. }\end{array}$ \\
\hline MELO ET AL. & $\begin{array}{l}\text { Refletir sobre a efetividade dos pla- } \\
\text { nos, programas e conferências pro- } \\
\text { duzidos e realizados pelo governo } \\
\text { federal no processo de construção } \\
\text { de políticas públicas para a popu- } \\
\text { lação LGBT no Brasil. }\end{array}$ & $\begin{array}{l}\text { O texto privilegia quatro docu } \neg \text { mentos que tratam da promoção dos } \\
\text { direitos humanos e da cidadania dessa população: o "Programa Brasil } \\
\text { Sem Homofobia", os "Anais da I Conferência Nacional LGBT", o "Plano } \\
\text { Nacional de Promoção da Cidadania e Direitos Humanos LGBT" e o } \\
\text { "Programa Nacional de Direitos Humanos". }\end{array}$ \\
\hline $\begin{array}{l}\text { VALADÃO E } \\
\text { GOMES } \\
2011\end{array}$ & $\begin{array}{l}\text { Analisar os modelos que podem } \\
\text { explicar a invisibilidade de lésbi- } \\
\text { cas e mulheres bissexuais na área } \\
\text { da assistência integral à saúde da } \\
\text { mulher. }\end{array}$ & $\begin{array}{l}\text { Lésbicas e mulheres bissexuais não têm apoio, por parte dos profis- } \\
\text { sionais de saúde, para verbalizar suas orientações sexuais quando } \\
\text { buscam assistência. Tal situação escamoteia um atendimento seguro, } \\
\text { produzindo exclusão e violência simbólica, apesar dos programas go- } \\
\text { vernamentais preconizarem o contrário. }\end{array}$ \\
\hline $\begin{array}{l}\text { MELO ET AL. } \\
2011\end{array}$ & $\begin{array}{l}\text { Analisar as políticas públicas de } \\
\text { saúde voltadas a população LGBT a } \\
\text { partir de entrevistas com gestores } \\
\text { governamentais e ativistas. }\end{array}$ & $\begin{array}{l}\text { O estudo aponta avanços para as políticas de atenção à população } \\
\text { LGBT com a criação do Programa Brasil sem Homofobia e a versão pre- } \\
\text { liminar da Política Nacional de saúde integral de LGBT. No entanto, a } \\
\text { implantação das ações ainda é um desafio. }\end{array}$ \\
\hline $\begin{array}{l}\text { BARBOSA E } \\
\text { FACHINE } \\
2009\end{array}$ & $\begin{array}{l}\text { Identificar a relação entre cuidados } \\
\text { em saúde de mulheres homosse- } \\
\text { xuais e representações de gênero, } \\
\text { sexualidade e corpo. }\end{array}$ & $\begin{array}{l}\text { Os resultados mostram uma maior dificuldade em acessar serviços gi- } \\
\text { necológicos para mulheres de baixa renda, aquelas que nunca tinham } \\
\text { tido sexo com homens, ou aquelas com imagem corporal masculiniza- } \\
\text { da. Fatores que dificultam o acesso são: representações e experiências } \\
\text { negativas quanto aos serviços de saúde, e construções indenitárias de } \\
\text { gênero e sexualidade. }\end{array}$ \\
\hline LIONÇO & $\begin{array}{l}\text { Problematizar a pertinência } \\
\text { de uma política de saúde para a } \\
\text { população de Gays, Lésbicas, Bis- } \\
\text { sexuais, Travestis e Transexuais - } \\
\text { GLBT. }\end{array}$ & $\begin{array}{l}\text { Aborda o desafio da construção de uma política de atenção integral } \\
\text { à saúde dessa população, tal como prevista no programa do gover- } \\
\text { no federal Brasil sem Homofobia. Implica a complexificação e o alar- } \\
\text { gamento do que se compreende por direitos sexuais e reprodutivos } \\
\text { para a efetiva promoção da equidade e da universalidade do acesso } \\
\text { aos bens e serviços. }\end{array}$ \\
\hline $\begin{array}{l}\text { ARAUJO ET } \\
\text { AL. } \\
2006\end{array}$ & $\begin{array}{l}\text { Descrever a experiência vivencia- } \\
\text { da por uma mulher homossexual } \\
\text { atendida em uma Unidade Básica } \\
\text { de Saúde. }\end{array}$ & $\begin{array}{l}\text { Fragilidade das relações interpessoais entre as mulheres e os profis- } \\
\text { sionais de saúde, com dificuldades de comunicação e não atenção às } \\
\text { questões vinculadas à sexualidade. }\end{array}$ \\
\hline $\begin{array}{l}\text { RAMOS E } \\
\text { CARRARA } \\
2006\end{array}$ & $\begin{array}{l}\text { Analisar os principais aspectos das } \\
\text { agendas do movimento homosse- } \\
\text { xual, e suas produções em conso- } \\
\text { nância com a academia. }\end{array}$ & $\begin{array}{l}\text { Um certo conhecimento vem sendo produzido como resultado da } \\
\text { interação entre o ativismo e a academia, no entanto, aponta-se a ne- } \\
\text { cessidade de muito esforço no sentido da participação e da expressão } \\
\text { do segmento como meio de produção de conhecimento que embase } \\
\text { políticas públicas. }\end{array}$ \\
\hline
\end{tabular}


heterossexualidade presumida, da falta de qualificação e do preconceito dos profissionais de saúde para atender a essa demanda (BARBOSA; FACCHINI, 2009).

De fato, a população LGBT, em decorrência da não adequação do gênero ao sexo biológico (sistema sexo/gênero) ou à identidade sexual heteronormativa, tem seus direitos humanos básicos agredidos e, muitas vezes, encontra-se em situação de vulnerabilidade (LIONÇO, 2008). Diante dessa realidade, o Ministério da Saúde reconhece que as identidades sexual e de gênero são atributos que expóem a população LGBT à discriminação e à violação de direitos humanos, inclusive ao acesso não integral à saúde (BRASIL, 2008).

Nesse sentido, Araujo et al (2006) afirmam que a população LGBT não tem suas necessidades de saúde contempladas por estar subordinada à homofobia, ou seja, à rejeição ou à intolerância irracional à homossexualidade. Os autores acrescentam que o grupo teme revelar a sua orientação sexual nos serviços de saúde, visualizando o impacto negativo que isso trará à qualidade da assistência.

Desse modo, esses mesmos autores identificam a relação profissional/usuário como primordial para a qualidade da assistência em saúde. No entanto, sua pesquisa evidencia a fragilidade dessa relação, principalmente no que tange ao processo de comunicação, no qual questóes importantes acerca da sexualidade acabam sendo omitidas, perdendo-se oportunidades para a promoção da saúde.

A população homossexual feminina enfrenta situações ainda mais especificas, conforme revelam Barbosa e Fachine (2009), que afirmam que mulheres lésbicas realizam com menor frequência exames preventivos $\mathrm{e}$ rotineiros, como o exame de prevenção contra o câncer de colo uterino (Papanicolau) e o exame de prevenção contra o câncer de mama (Mamografia).

Os motivos assinalados pelas mulheres para essa baixa procura dos serviços de saúde vão desde as reações discriminatórias por parte dos profissionais, após a revelação da orientação sexual, até a falta de especificidade lésbica nos serviços de saúde, vivenciada por consultas que não respondem às demandas do grupo (BARBOSA; FACHINE, 2009). A percepção equivocada quanto a haver menores riscos de Infecçóes Sexualmente
Transmitidas (IST) também é identificada como fator que dificulta a adesão das mesmas aos cuidados ginecológicos (VALADÃO; GOMES, 2011).

Partindo da concepção do levantamento das necessidades no setor da saúde, relacionadas à homossexualidade, Barbosa e Fachine (2009) abordam que, quando considerados os indicadores, os estudos revelam uma maior propensão ao envolvimento com tabagismo, uso de álcool e drogas ilícitas, obesidade, prática sexual sem proteção, demanda aumentada aos problemas mentais, IST's, bullying, câncer de colo de útero e de mama, HIV-Aids, comportamentos violentos, entre outros.

Quando se fala em violência, esse cenário torna-se ainda mais dramático. $\mathrm{O}$ impacto da violência na vida de pessoas LGBT é relatado em pesquisas como a de Ramos e Carrara (2006), que citam dados do Grupo Gay da Bahia (GGB), uma organização que, desde os anos 1980, arquiva informaçôes sobre a violência contra os homossexuais, tendo reunido registros documentados acerca de assassinatos de homossexuais com motivação homofóbica.

Dados mais atualizados do GGB atestam 1608 casos de homens homossexuais, lésbicas e transgêneros assassinados em crimes homofóbicos, entre os anos de 2001 e 2010, além de identificarem o Brasil como "campeão mundial em assassinatos" da população LGBT. O Nordeste é considerado a região com o maior índice de violência praticada contra o grupo, sendo responsável por $43 \%$ dos assassinatos (GGB, 2010).

Tais fatores devem-se, em grande parte, aos contextos social e cultural heteronormativos, que refletem a discriminação, o preconceito e a exclusão social sofrida por pessoas de orientação sexual e identidade de gênero discordantes dos padróes considerados "normais" pela sociedade, que, nesse caso, fundamenta-se como forte contribuinte para o distanciamento dos serviços e o envolvimento em situaçóes de agravo.

Entretanto, percebe-se uma evolução no contexto brasileiro relacionado ao grupo LGBT. A primeira delas refere-se à retirada do termo homossexualismo das terminologias da saúde, dando clareza para o caráter não patológico das relaçóes homoeróticas. Lionço (2008) faz menção, em seu artigo, a esse processo. $\mathrm{O}$ autor cita, inclusive, a Resolução 01/99, do Conselho Federal de 
Psicologia (CFP/1999), que orienta a atuação do psicólogo frente à diversidade sexual livre de preconceitos, discriminação e julgamentos. Discorre, ainda, sobre a Resolução 489/2006, do Conselho Federal de Serviço Social, que veta qualquer reação discriminatória motivada pela orientação sexual e pela identidade de gênero no exercício profissional do Assistente Social.

Nesse sentido, a partir de 2001, com a criação do Conselho Nacional de Combate à Discriminação (CNCD), vinculado ao Ministério da Justiça, as açóes dos grupos de ativismo LGBT, no Brasil, começaram, também, a priorizar a reivindicação de políticas públicas voltadas à promoção de sua cidadania e dos direitos humanos, para além da esfera de prevenção da epidemia de HIV/Aids e de apoio a suas vítimas, que já vinham surgindo desde meados da década de 1980 (MELO et al., 2012).

Ao longo dos anos 2000, é possível identificar outros marcos importantes para a garantia da dignidade homossexual. Em 2004, por exemplo, destaca-se a criaçâo do Brasil Sem Homofobia: Programa de Combate à Violência e à Discriminação contra LGBT e de Promoção da Cidadania Homossexual, com o objetivo de promover a cidadania do grupo, a partir da equiparação de direitos e do combate à violência e à discriminação homofóbica (MELO et al., 2012).

Nesse âmbito, Lionço (2008) acrescenta que o Brasil Sem Homofobia representa uma conquista da sociedade brasileira, decorrente de mais de duas décadas de mobilização social. O programa apresenta propostas intersetoriais, abrangendo açôes nos setores Saúde, Educação, Cultura, Trabalho e Segurança Pública.

Também foi lançado, pelo governo federal, em 2004, o documento Política Nacional de Atenção Integral à Saúde da Mulher: princípios e diretrizes, no qual se reconhece a necessidade de atenção, no atendimento à saúde, às particularidades de diferenciados segmentos de mulheres, como negras, indígenas e lésbicas. $\mathrm{Ou}-$ tra iniciativa que contemplou a população LGBT foi a Carta dos Direitos dos Usuários da Saúde, aprovada por meio da Portaria no 675, de 30 de março de 2006, na qual está explicitado o direito ao cuidado, ao tratamento e ao atendimento no âmbito do Sistema Único de Saúde (SUS), livre de discriminação por orientação sexual e identidade de gênero (MELO et al., 2012).

Nesse contexto, uma política nacional de saúde que contemple as especificidades LGBT começou a se materializar, em 2008, com o lançamento da versão preliminar do documento Política Nacional de Saúde Integral de LGBT, cuja versão final foi divulgada em 2010 (MELO et al., 2012). Entre as nove diretrizes que orientaram essa Política, destaca-se a inclusão de variáveis envolvendo a orientação sexual, identidade de gênero, ciclos de vida e raça-etnia nos processos de formulação e implantação de políticas e programas do SUS (BRASIL, 2008).

Melo et al (2011) destacam uma limitação importante para a efetivação dos programas e políticas LGBT: a ausência de previsão orçamentária para a execução das açóes previstas nos planos, e complementam afirmando que a escassez e, até mesmo, a ausência de recursos revelam as açôes como difíceis de serem alcançadas.

Logo, percebe-se que, apesar de as políticas e os programas LGBT apresentarem boas perspectivas, a materialização das propostas e ações realizadas ainda é desbravadora e desafiadora. Melo et al (2011) corroboram essa ideia, ao afirmarem que, apesar da existência de vários projetos, programas e outros compromissos do governo federal, relativos ao tema da saúde da população LGBT, o que se pode constatar é que ainda existem vários obstáculos no tocante à efetivação das propostas do governo.

Dois obstáculos, que podem ser considerados como magnos nesse contexto, são a homofobia e a heteronormatividade institucional. Assim, Lionço (2008) elucida que o processo de construção de serviços não discriminatórios na área da saúde enfrenta diversas barreiras diante de uma sociedade na qual a heterossexualidade se configura como um padrão amplamente difundido e cultuado.

Melo et al (2011) encontraram nas falas dos sujeitos de sua pesquisa discursos que, recorrentemente, reconhecem a presença de atendimentos discriminatórios nos serviços de saúde no país, o que remete ao longo caminho ainda a ser percorrido rumo à conscientização dos agentes de saúde quanto às consequências individuais e sociais da homofobia. 
Nesse sentido, as reformulações dos espaços de saúde para a inclusão da população LGBT também dependem das transformaçôes no modo de pensar e de agir dos profissionais de saúde. As questôes culturais advindas do padrão heteronormativo influenciam, de modo subjetivo, o atendimento dos profissionais da saúde, o que os leva a assistir todos os usuários como se fossem heterossexuais, o que gera situaçóes graves de discriminação e preconceito contra lésbicas, gays, bissexuais, travestis e transexuais (CARDOSO; FERRO, 2012).

Logo, a sensibilização dos profissionais da saúde quanto ao atendimento livre de preconceitos e julgamentos é um dos temas mais recorrentes nos planos, programas e demais documentos que apresentam diretrizes, objetivos e metas para as políticas públicas de saúde formuladas para o público LGBT (MELO et al., 2011).

Dessa forma, ainda, ressalta-se que é necessário que os profissionais da área da saúde desenvolvam maior proximidade com as políticas públicas e com as problemáticas específicas da população LGBT para a qualificação dos serviços prestados por suas diversas áreas (LIONÇO, 2008).

Sendo assim, é necessário que os princípios de universalidade, integralidade e equidade, constitutivos do SUS, sejam materializados em políticas públicas que promovam o enfrentamento das consequências excludentes da homofobia e da heteronormatividade. Do contrário, continuarão a existir barreiras simbólicas, morais e estéticas que impeçam o acesso da população LGBT a serviços de saúde de qualidade (MELO et al., 2011).

\section{Conclusões}

A homossexualidade é historicamente contextualizada com o preconceito e a discriminação, inclusive quando se aborda o atendimento no âmbito da saúde pública. Assim, o acesso dessa população aos serviços de saúde tem sido descrito como injusto e excludente, e, consequentemente, como uma vulnerabilidade do grupo LGBT.

Percebem-se, nesse campo específico, avanços em programas e políticas públicas. Entre eles, destacam-se: o programa Brasil sem Homofobia, a Política Nacional de Atenção Integral à Saúde da Mulher, a Carta de Direitos dos Usuários da Saúde e a Política Nacional de Saúde Integral de LGBT.

Entretanto, apesar das boas perspectivas das ações propostas por essas políticas e programas, a efetivação das mesmas ainda configura-se como desafiadora. As consequências da homofobia e da heteronormatividade institucional, caracterizadas pelos atendimentos discriminatórios, são as principais causas da exclusão da população pesquisada dos espaços de saúde.

A maioria das pesquisas revisadas menciona a urgência de sensibilizar e capacitar os recursos humanos da saúde com relação às especificidades da saúde LGBT. É necessário que os profissionais do setor tenham maior proximidade com as políticas públicas e com as problemáticas específicas da população LGBT para a qualificação dos serviços prestados pelas diversas áreas.

Nesse sentido, é imperiosa a efetivação dos princípios constitutivos do SUS, de universalidade, integralidade e equidade, expressos em políticas públicas que de fato promovam o enfrentamento da homofobia e da heteronormatividade nos serviços de saúde.

Ademais, percebe-se a escassez de pesquisas que abordem o assunto, o que dificulta o conhecimento acerca da real situação da saúde do grupo. Logo, recomenda-se o estímulo a estudos que busquem conhecer tal relação, como forma de gerar dados que fomentem, inclusive, a formulação de outras políticas que efetivamente aproximem o grupo LGBT dos espaços de saúde.

\section{Referências}

ARAÚJO, M. A. L. et al. Relação Usuária-Profissional de saúde: Experiência de uma mulher homossexual em uma Unidade de Saúde de referência de Fortaleza. Escola Anna Nery, v.10, n. 2, p. 323-7, ago. 2006
ABDO, C. H. N.; GUARIGLIA FILHO, J. E. F. A mulher e sua sexualidade. In: CORDÁS, T. A.; SALZANO, F. T. Saúde mental da mulher. São Paulo: Editora Atheneu, 2004. p. 229-268. 
BARBOSA, R. M., FACCHINI, R. Acesso a cuidados relativos à saúde sexual entre mulheres que fazem sexo com mulheres em São Paulo, Brasil. Cadernos de Saúde Pública, Rio de Janeiro, v. 25, suppl 2, p. 291-300, 2009.

BRASIL. Política nacional de saúde integral de Lésbicas, Gays, Bissexuais, Travestis e Transexuais. Brasília: Ministério da Saúde, 2008.

CARDOSO, M. R.; FERRO, L. F. Saúde e População LGBT: Demandas e Especificidades em Questão. Psicologia: ciência e profissão, v. 32, n.3, p.552-563, 2012.

CARRARA, S. Políticas e direitos sexuais no Brasil contemporâneo. BAGOAS, n. 05, p. 131-147, 2010.

GUTIÉRREZ, N. I. M. Siyuación de salud sexual y reproductiva, hombres y mujeres homosexuales hospital Maria Auxiliadora. Revista Peruana de Obstetricia y Enfermería, v. 3, n. 1, p. 02-16, 2007.

GRUPO GAY DA BAHIA. Tabela geral de assassinatos de homossexuais no Brasil, 2010. Disponível em: <http://www.ggb.org.br/ imagens/Tabela\%20geral\%20Assassintos\%20de\%20Homossexual\%20Brasil\%202010.pdf>. Acesso em: 27 jul. 2013

HECK, J., RANDALL, V., GORIN, S. S. Health care access among individuals involved in same-sex relationships. American Journal of Public Health, v. 96, n. 6, p. 1111-1118, 2006.

LIONÇO, T. Que Direito à Saúde para a População GLBT? Considerando Direitos Humanos, Sexuais e Reprodutivos em Busca da Integralidade e da Equidade. Saúde e Sociedade, São Paulo, v.17, n.2, p.11-21, 2008

LOURO, G. L. Gênero, sexualidade e educação: uma perspectiva pós-estruturalista. Rio de Janeiro: Vozes, 1997.

MENDES, K. D. S.; SILVEIRA, R. C. C. P.; GALVÃO, C. M. Revisão integrativa: método de pesquisa para a incorporação de evidências na saúde e na enfermagem. Texto \& Contexto-Enfermagem. n. 17, v. 4, p.758-64, 2008.

MELLO L. et al. Por onde andam as Políticas Públicas para a Po- pulação LGBT no Brasil. Revista Sociedade e Estado, v. 27, n. 2, maio 2012.

MELLO, L. et al. Políticas de saúde para lésbicas, gays, bissexuais, travestis e transexuais no Brasil: em busca de universalidade, integralidade e equidade. Sexualidade, Salud e Sociedad, n.9, p. 7-28, 2011.

PEREIRA, H; LEAL, I. P. A identidade (homo)sexual e os seus determinantes: implicações para a saúde. Análise Psicológica, v. 3, n. 23, p. 315-322, 2005.

PISCITELLI, A. Re-criando a (categoria) mulher? 2001. Disponível em: $\quad$ <http://www.pagu.unicamp.br/sites/www.ifch.unicamp. br.pagu/files/Adriana01.pdf>. Acesso em: 27 jul. 2013

RAMOS, S. CARRARA, S. A Constituição da Problemática da Violência contra Homossexuais: a Articulação entre Ativismo e Academia na Elaboração de Políticas Públicas. PHYSYS: Revista de Saúde Coletiva, Rio de Janeiro, v. 16, n. 2, p. 185-205, 2006.

TONIETTE, M. A. Um breve olhar histórico sobre a homossexualidade. Revista Brasileira de Sexualidade Humana, São Paulo, v. 17, n. 1, 2006.

VALADÃO, R. C.; GOMES, R. A homossexualidade feminina no campo da saúde: da invisibilidade à violência. PHYSIS - Revista de Saúde Coletiva, Rio de Janeiro, v. 21, n. 4, p. 1451-1467, 2011.

Recebido para publicação em julho de 2013

Versão definitiva em dezembro de 2013

Suporte financeiro: não houve

Conflito de interesse: inexistente 